\title{
ANNOTATIONS
}

\section{F.R.C.S. (with Ophthalmology)}

The first examination for the F.R.C.S. (with ophthalmology) has been held and one candidate has received the diploma. Although the entry was not a large one, it is expected that it will grow in the future, as no doubt the leading London hospitals in the course of time will demand this qualification for Ophthalmologists. The examination consisted of two papers, a clinical examination, viva voce, and examination in operative surgery on pigs' eyes. The questions in the papers are given below.* The questions are simple and straightforward, and unless a very high standard was required in answering them they are no more difficult than those set for the D.O.M.S. examination. The clinical examination consisted of a written commentary on a case and a viva voce on a number of other cases. Pathological specimens were also exhibited. We sympathize with any candidate who has to operate on pigs' eyes, in their flabby halfmacerated condition, under the tension of an examination, and we can only suppose that the examiners mark according to the manner in which the candidate exhibits his knowledge of the use of the instruments employed.

\section{The Use of Light as an Aid to Aerial Navigation}

Last September we dealt with the question of dazzling by motor headlights and discussed some of the remedies suggested. So far no perfect solution seems to have been found. The same problem has also to be faced in aerial navigation with the added difficulty of the greatly increased speed attained by aircraft. Colonel Blandy read a paper before the Illuminating Engineering Society and the Royal Aeronautical Society's joint meeting last January in which he dealt with the whole question of the use of light as an aid to aerial navigation. The International Convention for aerial navigation in Annexe D, Section 1, contains certain proposed "Rules as to

* F.R.C.S. (with Ophthalmology) Examination Papers

PAPER No. 1.-All questions must be answered. (1) Describe the origin, insertion, nerve supply, action and relations of the Levator Palpebrae Superioris, and the Inferior Oblique. (2) Describe the structures and their functions by which tears pass from the conjunctival sac to the nose. (3) To what is the normal intra-ocular pressure due, and how is it maintained ? (4) Describe, with the aid of diagrams, the theory of retinoscopy.

PAPER No. 2.-All questions must be answered. (1) How may secondary glaucoma be produced? Indicate your treatment for the various conditions. (2) Write an account of glioma of the retina giving its minute structure and clinical appearances. (3) Describe the concussion changes which are met with in the retina, choroid and optic nerve. 
Lights" and there states that the prescribed navigation lights must not be dazzling. The word is not further defined and, owing to the intense darkness in which night air navigation is frequently done, it may be found that the solution of the problem may be a very difficult task. The Convention also prescribed that aircraft should carry four lights, a white one at the bows and at the stern, visible at a distance of eight kilometres, a green one on the right side and a red one on the left side, each visible at five kilometres. Colonel Blandy pointed out that in the case of two approaching aircraft travelling at the rate 3.3 miles per minute the white light would be visible 90 seconds before meeting and the side lights only 50 seconds. The range of visibility, particularly of the side lights, may well have to be increased in the near future. In addition, a carefully designed screen has to be devised in order to eliminate the fringe angle without interfering with even illumination over the prescribed dihedral angle of 110 degrees. Another difficulty has been found in obtaining the correct formula for the tinting of the coloured glasses. That given by the present methods does not work well when high intensity filaments are used. Many other interesting optical problems in connection with aerial lighthouses, the illumination of landing grounds and aerodromes, and the internal lighting of the craft itself have also to be dealt with. A full report of Colonel Blandy's paper and the subsequent discussion in which several well-known air-men took part will be found in the February number of "The Illuminating Engineer."

\section{ABSTRACTS}

\section{I.-THE ESTIMATION OF THE LOSS OF WORKING CAPACITY IN TRAUMATIC CATARACT}

Rasquin, E.-The estimation of the loss of working capacity in traumatic cataract. (L'évaluation de la réduction de capacité de, travail dans la cataracte traumatique.) Arch. med. belges, November, 1918.

Rasquin points out that, in spite of numerous discussions on the subject, the question of the exact amount of loss of efficiency due to traumatic cataract is still very unsettled. The GuideBarème des Invalidités of France makes no mention of it directly, but says that, whatever the nature of the lesion, the degree of visual acuity is to be taken as the base in calculating the loss, and also that paralysis of accommodation, which is frequently associated with a dilated pupil, is to be regarded as an infirmity reckoned at 5 to 20 . 